\title{
A Multilevel Analysis of Trends and Predictors Associated with Teenage Pregnancy and Early Motherhood in Zambia (2001 - 2018)
}

Million Phiri ( $\nabla$ million.phiri@unza.zm )

University of Zambia

Mwewa E. Kasonde

University of Zambia

Nkuye Moyo

University of Zambia

Milika Sikaluzwe

University of Zambia

Simona Simona

University of Zambia

\section{Research}

Keywords: Teenage girls, Pregnancy, Early Motherhood, Trends, Multilevel analysis, DHS Zambia

Posted Date: January 4th, 2022

DOI: https://doi.org/10.21203/rs.3.rs-1178770/v1

License: (c) (1) This work is licensed under a Creative Commons Attribution 4.0 International License. Read Full License 


\section{Abstract}

\section{Introduction}

Teenage pregnancy remains a major social and public health challenge in developing countries especially sub-Saharan Africa (SSA) where prevalence rates are still increasing. Even if considerable effort has been made over the years to study determining factors of teenage pregnancy in SSA, few studies have looked at the trends and associated factors over a longer period. Furthermore, no known study has focussed on both individual and contextual factors influencing teenage pregnancy in Zambia. This study, thus sought to fill this gap in knowledge by simultaneously investigating trends of teenage pregnancy and early motherhood as well as its individual and contextual determining factors.

\section{Methods}

A total pooled weighted sample of 10,010 teenagers (in the age group 15 to 19) from four waves of the Zambia Demographic and Health Surveys (ZDHS) were extracted. Using bivariate analysis, we investigated the trends of teenage pregnancy between 2001 and 2018. Separate multilevel logistic regression models were fitted on pooled teenage pregnancy data in relation to several individual and contextual level factors. Both fixed and random effects were produced. Parameter estimates were produced using Bayesian Markov chain Monte Carlo (MCMC) Methods in BRMS.

\section{Results}

Results show that the trends of teenage pregnancy in Zambia have shown an overall decrease of $2 \%$ between 2001 and 2018. Almost all the socioeconomic and demographic variables were consistently associated with teenage pregnancy $(p<0.001)$ in a bivariate analysis across the four ZDHS waves. In multilevel analysis, the odds of being pregnant were higher for teenagers who were aged between 18 and 19 years $(\mathrm{AOR}=2.57,95 \% \mathrm{Cl}: 2.20-2.98)$, employed $(\mathrm{AOR}=1.24,95 \% \mathrm{Cl}: 1.06-1.46)$ married $(\mathrm{AOR}=8.33$, $95 \% \mathrm{Cl}: 6.84-10.26)$ and those with knowledge of fertile period ( $\mathrm{AOR}=1.69,95 \% \mathrm{Cl}: 1.43-2.00)$. On the other hand, being in higher wealth quintile, 15-17 years of age, exposure to family planning messages and delayed sexual debut were associated with decreased odds of early teenage pregnancy.

\section{Conclusion}

The study shows that early pregnancy remains a social and public health challenge in Zambia as the country has seen little decrease in the prevalence over the years under consideration. Factors associated with teenage pregnancy and early motherhood include age, marital status, and employment, knowledge of fertility period, wealth quintile, sexual debut and exposure to mass-media family planning messaging. Concerted effort must be made to improve literacy levels, reduce poverty and enhance sexual health promotion through the mass media in view of cultural norms, which may prevent parents and children from discussion sexual education topics thus exacerbate the vice. 


\section{Plain English Summary}

Teenage pregnancy continues to be a major social and public health challenge in developing countries, particularly in Sub-Saharan Africa (SSA), where prevalence rates are on the rise. Even if considerable effort has been made over the years to study determining factors of teenage pregnancy in SSA, few studies have looked at the trends and associated factors over a longer period. This study, thus sought to fill this gap in knowledge by simultaneously investigating trends of teenage pregnancy and early motherhood as well as its individual and contextual determining factors. Here, we used a pooled dataset from Zambia's 2001 to 2018 DHS to run separate multilevel logistic regression models to examine several individual and contextual level factors influencing teenage pregnancy and early motherhood. Findings show that trends of teenage pregnancy in Zambia have shown an overall decrease of only $2 \%$ between 2001 and 2018. Almost all the socioeconomic and demographic variables were consistently associated with teenage pregnancy and early motherhood. The study shows that early pregnancy remains a social and public health challenge in Zambia as the country has seen little decrease in the prevalence over the years under consideration. Concerted effort must be made to improve literacy levels, reduce poverty and enhance sexual health promotion through the mass media in view of cultural norms, which may prevent parents and children from discussion sexual education topics thus exacerbate the vice.

\section{Introduction}

Teenage pregnancy can be defined as the occurrence of pregnancy among young girls between 10 and 19 years $(1,2)$. It is a major social and public health problem for both developing and developed countries. The prevalence rates for teenage pregnancy stands at $18.8 \%$ while that of sub-Saharan Africa is around $19.3 \%$ (3). The drivers of teenage pregnancy are several and multifaceted and these include poverty, inadequate education and employment opportunities, gender inequalities, rural residence, poor access to contraceptives and inadequate sexual and reproductive health information among others (35). Marital status is another major factor associated with teenage pregnancy. In many societies, girls are under immerse pressure to get married and the social status that is associated with childbirth means that married young girls have subsequent pressure to bear children (6). It is for this reason that about $90 \%$ of all teenage pregnancy occur within marriage (7).

Teenage pregnancy and early motherhood come with a great deal of health risks and complications for both the teenagers themselves and their babies. The World Health Organization (WHO) estimates that $99 \%$ of deaths among women age 15-49 are due to pregnancy and childbirth complications among teenage girls age 15-19 globally $(8,9)$. Further, some 3.9 million unsafe abortions among girls age 15-19 years occur each year, contributing to maternal mortality, morbidity and lasting health problems. This phenomena may be exacerbated during the era of the COVID-19 pandemic that disrupted provision of sexual and reproductive health services among teenagers and young mothers (10). Additionally, babies born from teenage mothers face higher risk of low birth weight, preterm delivery and severe neonatal conditions. Younger mothers are also prone to violence by an intimate partner (9); a vice that increases their exposure to poor maternal health outcomes. At a global level, population growth tends to be more 
rapid when women are exposed to early childbirth as this will lengthen the reproductive period and thus, increase fertility rate (12).

In Zambia, just like most parts of sub-Saharan Africa, teenage pregnancy and early motherhood is high and a prominent issue in social, political, and cultural discourse. In 2015, teenage fertility was estimated at $28.5 \%$ (8), making Zambia one of the countries with significantly high prevalence of teenage motherhood among sub-Saharan African countries. The prevalence rates, however, have notably been in decline from $37 \%$ in 1992 to $28.5 \%$ in 2018 albeit with significant within country variations. The prevalence is significantly higher in rural areas (37\%) compared to urban areas (19\%) (13). Teenage fertility in Zambia is reported to be twice as high as that of sub-Saharan African region (2).

Although the prevalence of teenage pregnancy and early motherhood appears to be falling overtime, it remains unacceptably high. These levels of teenage fertility signify the fact that more needs to be done to stimulate a further reduction in fertility levels among this demographic at a health policy level. Doing so requires a holistic understanding of factors associated with teenage pregnancy. This understanding of factors affecting adolescent fertility is much more lacking when we consider individual and contextual factors. Therefore, this study was designed to fill the gap in knowledge as well as make policy suggestions aimed at a reduction in teenage pregnancy rates in the country. This study aimed to investigate factors associated with teenage pregnancy and early motherhood in Zambia. The study also sought to establish if there are community variations in teenage pregnancies and early motherhood. Unlike a similar study conducted in Zambia (4), this study incorporates a trend and contextual analysis as well as use of complex and comprehensive dataset. These objectives were accomplished by making use of the nationally representative sample from the Zambia Demographic and Health Survey (ZDHS) data gathered between 2001 and 2018. To establish if the factors associated with teenage pregnancy and early motherhood vary between communities, we conducted a two-level multilevel analysis in view of the hierarchical ZDHS data structure of individual women who are nested within clusters.

\section{Methods And Data}

\subsection{Study design and sampling procedure}

This study is based on secondary micro data analysis of the existing national level data from the ZDHS programme. The ZDHS is a national representative household survey conducted by the Zambia Statistics Agency with support from global partners including the ICF International and USAID. A detailed description of the methods used in the DHS are published elsewhere (13). For this study, we extracted all relevant variables from the women data files (Individual recode) in the 2001-02, 2007, 2013-14 and 2018 ZDHS data sets. The DHS uses two-stage sampling to select enumeration areas (EAs) in the first stage and households in the second stage. The nature of DHS data allows for comparisons between variables over time, thus allowing monitoring changes in the indicators of variables of interest in different geographical areas (15). Women age 15-49 years of selected households who had accepted to participate in the study were also enrolled to participate in the survey. The data analysed in this study 
relate to teenage girls age $15-19$ years. The four DHSs used in the analysis captured a pooled weighted sample of 10,010 teenagers. The distribution of sample sizes per survey year is reported in table 2 .

\subsection{Study variables}

\subsubsection{Outcome variable}

The outcome variable of interest in this study was teenage pregnancy and early motherhood. This variable comprised of two variables captured in the ZDHS. The first one captured teenagers who have had a live birth and the second included teenagers who were pregnant with their first child at the time of the survey (15). The dependent variable was binary and coded as " 1 " for teenage who either had started childbearing or were pregnant for the first time and coded " 0 "if otherwise. Data in this study only includes current or prior pregnancies. The data did not include teenage pregnancies that resulted in abortions, whether spontaneous or induced or a stillbirth.

\subsubsection{Independent variables}

Based on existing literature, we identified potential factors that could influence teenage pregnancy in Zambia at two levels (individual and community). The individual levels variables included socioeconomic, demographic, health and environmental factors. DHS reference materials and data collection forms were used to identify the individual level independent variables presented in (Table 1). 
Table 1

Definition of predictor variables

\begin{tabular}{|c|c|c|}
\hline No & Variable name & Definition and measurement \\
\hline 1 & Age & $\begin{array}{l}\text { Age of teenage respondents at time of survey: range from } 15-19 \\
\text { years }\end{array}$ \\
\hline 2 & Marital status & $\begin{array}{l}\text { Current marital status of teenager; } 1=\text { Never married; } \\
2=\text { Married/Living with partner; } 3=\text { Formerly married }\end{array}$ \\
\hline 3 & Literacy & Ability to read: $1=$ Able to read; $2=$ Cannot read at all \\
\hline 4 & Age at first sex & $\begin{array}{l}\text { Age at which teenager reported having first sexual encounter; } 1=10- \\
14 \text { years; } 2=15-17 \text { years; } 3=18-19 \text { years }\end{array}$ \\
\hline 5 & Education level & $\begin{array}{l}\text { Education level attained by teenager; } 1=\text { No education; } 2=\text { Primary; } 3= \\
\text { Secondary; } 4=\text { Tertiary }\end{array}$ \\
\hline 6 & Wealth status & $\begin{array}{l}\text { Income classification of households where teenagers belong; } \\
\text { 1=Poorest; } 2=\text { =Poor; } 3=\text { Middle; } 4=\text { Rich; } 5=\text { Richest }\end{array}$ \\
\hline 7 & Employment status & Employment status of teenagers: 1 =Employed; 2 =Unemployed \\
\hline 8 & $\begin{array}{l}\text { Exposure to mass- } \\
\text { media FP messages }\end{array}$ & Access to mass-media family planning messages: $1=\mathrm{No} ; 2=\mathrm{Yes}$ \\
\hline 9 & $\begin{array}{l}\text { Knowledge of FP } \\
\text { method }\end{array}$ & $\begin{array}{l}\text { Teenagers' have knowledge of any modern contraceptive method: } \\
0=\text { Knows no method; } 1=\text { Knows a method }\end{array}$ \\
\hline 10 & $\begin{array}{l}\text { Knowledge of ovulation } \\
\text { period }\end{array}$ & $\begin{array}{l}\text { Teenagers' have knowledge of ovulation period: } 1=\text { Knowledgeable; } \\
2=\text { Don't know }\end{array}$ \\
\hline 11 & $\begin{array}{l}\text { Visited health facility in } \\
\text { last } 12 \text {-months }\end{array}$ & $\begin{array}{l}\text { Teenager who visited health facility in past } 12 \text { month prior to survey: } \\
1=\text { No; } 2=\text { Yes }\end{array}$ \\
\hline
\end{tabular}

Community-level variables were created by aggregating individual level data into clusters and these included community poverty, community education and community knowledge of family planning methods, place of residence and geographical region. All community level variables are categorized as 'low' and 'high' representing the magnitude of the phenomena being studied at the cluster level. Place of residence and geographical region retained original categorizations.

Place of residence is one of the criteria utilised in designing the sample to estimate the prevalence of core demographic and health indicators at the national level. It is categorized as 'rural' and 'urban'. Region was defined as the geographical location where population resides, it directly explains community characteristics. Region variable classifies the ten (10) administrative regional provinces of Zambia namely, Central, Copperbelt, Eastern, Luapula, Lusaka, Muchinga, Northern, North-Western, Southern and Western provinces. All the regions were independently encoded.

\subsection{Statistical analysis}


The initial analysis of data was performed using Stata version 14.2 (Stata Corp. Inc. Texas, USA) taking into consideration survey design, cluster effect and post-stratification weights. Key socio-economic and demographic factors were described and expressed in frequency and percentage distributions over time. Trend analysis of teenage pregnancy was conducted relative to the respective survey years (between 2001 and 2018). Exploratory bivariate analysis was carried out separately for each dataset to assess the association between the prevalence of teenage pregnancy and early motherhood and the selected independent variables outlined in Table 2.

A two-level multilevel binary logistic regression model was applied on pooled data for all the four surveys to assess the effects of several individual and community level factors on teenage pregnancy in Zambia. Adjusted odds ratios (AOR) with corresponding 95\% confidence intervals $(\mathrm{Cl})$ were reported. Three multilevel logistic models were estimated. Model 1 included only the intercept and the outcome variable. Model 2 included the individual level variables while Model 3 had both the individual and community level variables. All significantly associated factors from the bivariate analyses were included in multilevel analysis. In addition, interesting covariates were included in the multilevel analyses regardless of their significant levels. The multilevel model assesses the probability $p_{i j}$ of a teenage woman or teenage $i$ in a community $j$ having early pregnancy. This analysis is represented as:

$$
\operatorname{logit}\left(p_{i j}\right)=\beta_{0}+\beta\{\backslash \mathrm{rm} \mathrm{X}\}_{i j}+u j+v
$$

Where $X_{i j}$ is a vector of independent variables at individual and community levels. $u j$ is normally distributed with variance $\sigma_{u}^{2} ; v$ is normally distributed with variance $\sigma_{u}^{2}$.

In terms of variances used to understand the variations of relationships between communities and the relative effect of community-level variables, the variance partition coefficient (VPC) was used. VPC provides information on the share of variance at each level. The latent method was used to calculate the VPC at each level. It assumes a threshold model, approximating the level 1 variance by $\Pi^{2} / 3(\approx 3.29$ ) $(16,17)$. The community level variance is calculated as follows:

$$
V P C_{\text {Community }}=\frac{\sigma_{u}^{2}}{\sigma_{u}^{2}+\Pi^{2} / 3}
$$

Parameter estimates were implemented using Bayesian inference through the Hamiltonian Monte-Carlo (HMC) in Stan but called from R using the BRMS package (18). Non-informative uniform prior distributions with large variances were used. Two chains were specified running for 2000 iterations with 500 warm-up length in order to achieve convergence. The convergence of chains was assessed by inspection of trace and auto-correlation plots. This was used to evaluate the goodness of fit of the models. For model comparisons and assessment of goodness of fit, Wanatabe - Aikake Information Criteria (WAIC) was used (19). The study is based on the ZDHS data, which is publicly available on (https://dhsprogram.com/) 


\section{Results}

\subsection{Trends in teenage pregnancy and early motherhood in Zambia, $2001-2018$}

The overall patterns in the trends show that over the period 2001 to 2018, teenage pregnancy and early motherhood had slightly reduced from $32-29 \%$ in Zambia. Bivariate analysis reveal that many socioeconomic and demographic variables were consistently associated with teenage pregnancy and early motherhood $(p<0.001)$. The percentage of teens who begun childbearing was highest in all the survey years among the 19 year olds and lowest among the 15-year-olds. The percentage of teenage pregnancy among 15-year-olds increased from 4.5-6.4\% between 2001 and 2018.

Teenage pregnancy and early motherhood have been consistently high in rural areas and among those with primary or no formal education $(\mathrm{p}<0.001)$. Teenage pregnancy has been generally high across the three education level categories (no education, primary and secondary). Among those with no education, prevalence had dropped from $54-42 \%$ in the period 2007 to 2018 Further, teenagers who were illiterate were more likely to become pregnant than those who were literate $(p<0.001)$.

Differences in prevalence of teenage pregnancy and early motherhood according to marital status were statistically significant across the four ZDHS's $(p<0.001)$. Married and formerly married teenagers comprised the highest prevalence of teenage pregnancy and early motherhood compared to those who reported to have been never married. For example, in $2018,89 \%$ of the married teens versus $18 \%$ of those never married were either pregnant or had begun childbearing. The difference could be attributed to frequent exposure to sexual intercourse among teens who were married. Further, early sexual debut was also found to be associated with a higher risk of teenage pregnancy and early motherhood in 2007 and 2018 ZDHS.

Similarly, study results show variations in prevalence of teenage pregnancy and early motherhood and household wealth status $(p<0.001)$. Teenagers from poor households had higher rates of teenage pregnancy and early motherhood compared to those from rich families. In $2018,8 \%$ of teens who belonged to richest household compared to $46 \%$ from poorest households had begun childbearing.

We also found that teenagers who were exposed to media family planning messages had lower risks of being pregnant or becoming a mother before age 20 in 2001, 2007 and 2018. Trends show a reduction in teenage pregnancy from 28-24\% between 2001 and 2018 among teenagers who were exposed to media family planning messages. However, knowledge of contraceptive method and visiting a health facility in the last 12 months were negatively associated with teenage pregnancy and early motherhood. 
Table 2

Percentage distribution of teenage pregnancy and early motherhood by background characteristics, 2001 -2018 DHS, Zambia

\begin{tabular}{|c|c|c|c|c|}
\hline \multirow[t]{3}{*}{ Background Characteristic } & $2001-2$ & 2007 DHS & 2013-14 DHS & 2018 DHS \\
\hline & \multicolumn{4}{|l|}{ DHS } \\
\hline & $N=1,811$ & $\mathrm{~N}=1,574 \%$ & $\mathrm{~N}=3,625 \%$ & $N=3,000$ \\
\hline Age & $\star \star \star$ & $\star \star \star *$ & $\star \star \star$ & $\star \star \star *$ \\
\hline 15 & 4.5 & 5.8 & 4.9 & 6.4 \\
\hline 16 & 15.0 & 16.2 & 11.9 & 15.1 \\
\hline 17 & 33.8 & 28.7 & 25.7 & 30.0 \\
\hline 18 & 44.2 & 41.0 & 41.7 & 41.9 \\
\hline 19 & 56.9 & 54.6 & 58.9 & 52.9 \\
\hline \multicolumn{5}{|l|}{ Residence } \\
\hline Urban & 27.1 & 20.4 & 20.0 & 19.3 \\
\hline Rural & 34.9 & 35.0 & 36.4 & 37.0 \\
\hline Educational level & $\star \star \star *$ & $\star \star \star ~$ & 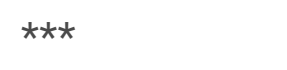 & $\star \star \star *$ \\
\hline No education & 45.6 & 54.3 & 53.2 & 41.9 \\
\hline Primary & 35.7 & 32.9 & 35.8 & 36.3 \\
\hline Secondary & 21.4 & 20.8 & 23.1 & 22.8 \\
\hline Higher & 0.0 & 0.0 & 6.7 & 20.0 \\
\hline Literacy & $\star \star \star *$ & $\star \star \star ~$ & $\star \star \star ~$ & $\star \star \star ~$ \\
\hline Illiterate & 41.0 & 42.8 & 44.1 & 47.7 \\
\hline Literate & 25.3 & 22.5 & 24.4 & 23.3 \\
\hline Employment & $\star \star \star$ & $\star \star \star$ & $\star \star \star \star ~$ & $\star \star \star$ \\
\hline No & 24.5 & 24.3 & 23.8 & 24.9 \\
\hline Yes & 46.3 & 43.0 & 47.5 & 49.5 \\
\hline Wealth quintile & $\star \star \star *$ & 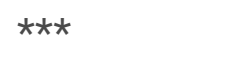 & $* \star \star$ & 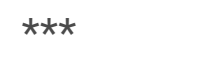 \\
\hline Poorest & 36.3 & 37.2 & 44.5 & 46.2 \\
\hline Poorer & 40.3 & 34.4 & 38.6 & 38.0 \\
\hline
\end{tabular}

*** $p<0.001 ;{ }^{* *}=p<0.01 ; *=p<0.05 ;$ ns $=$ non-significant 


\begin{tabular}{|c|c|c|c|c|}
\hline \multirow[t]{3}{*}{ Background Characteristic } & 2001-2 & 2007 DHS & 2013-14 DHS & 2018 DHS \\
\hline & \multicolumn{4}{|l|}{ DHS } \\
\hline & $\mathrm{N}=1,811$ & $\mathrm{~N}=1,574 \%$ & $\mathrm{~N}=3,625 \%$ & $\mathbf{N}=3,000$ \\
\hline Middle & 34.9 & 36.7 & 34.5 & 35.0 \\
\hline Richer & 36.4 & 29.4 & 28.2 & 27.0 \\
\hline Richest & 16.3 & 14.0 & 10.3 & 7.6 \\
\hline Marital status & *** & $\star \star \star *$ & $\star \star \star$ & $\star \star \star \star ~$ \\
\hline Never married & 13.1 & 14.2 & 14.4 & 18.1 \\
\hline Married & 82.9 & 85.0 & 91.3 & 89.0 \\
\hline Formerly married & 70.4 & 81.8 & 82.0 & 91.2 \\
\hline Knows fertile period & ns & ** & ns & ns \\
\hline No & 31.0 & 26.3 & 28.1 & 29.1 \\
\hline Yes & 34.6 & 36.3 & 30.9 & 30.0 \\
\hline Age at first sex & ns & * & ns & $\star \star \star$ \\
\hline $10-14$ & 51.5 & 53.5 & 51.9 & 65.2 \\
\hline $15-17$ & 52.7 & 57.1 & 56.2 & 59.5 \\
\hline $18-19$ & 36.6 & 35.9 & 47.2 & 41.3 \\
\hline Knowledge of any contraceptive method & *** & $\star \star \star$ & $\star \star \star$ & $\star \star \star *$ \\
\hline No & 6.2 & 11.1 & 9.2 & 6.7 \\
\hline Yes & 33.4 & 29.7 & 29.5 & 30.5 \\
\hline Exposure to media FP messages & * & ns & $\star \star$ & * \\
\hline No & 34.0 & 29.2 & 30.2 & 30.4 \\
\hline Yes & 28.4 & 25.7 & 24.4 & 23.5 \\
\hline Visited health facility last 12 months & $\star \star \star *$ & $\star * \star$ & $\star \star \star *$ & $\star * *$ \\
\hline No & 15.8 & 18.2 & 17.0 & 15.2 \\
\hline Yes & 49.4 & 55.4 & 49.2 & 45.6 \\
\hline Total & 31.6 & 27.9 & 28.5 & 29.2 \\
\hline
\end{tabular}




\subsection{Multilevel analysis of predictors of teenage pregnancy and early motherhood in Zambia 2002-2018}

The multilevel analysis results are presented using the posterior odds ratios and 95\% Bayesian credible intervals (Crl) for each of the variables included in all models. Statistical significance is determined by non-inclusion of " 1 " in the $95 \%$ (Crl). Both the fixed and random effects are reported. Individual and community level predictors of teenage pregnancy and early motherhood are reported in Table 3 . The results are displayed in three models with model 1 being the null model showing results from the random intercept multilevel analysis without individual and community level variables. This is intended to show the level of heterogeneity between clusters and indicate variations in teenage pregnancies attributable to differences in clusters. The variance partition coefficient VPC of $10.4 \%$ (i.e. $.38 /(.38+3.29)$ ) from the variance component model before all independent variables are controlled for shows significant contribution of community (cluster) level variables to variations in total teenage pregnancies in Zambia.

Table 3 also shows features for model comparisons. After adjusting for the effects of all observable individual and community level variables, about $8.6 \%$ of the total unexplained variation in teenage pregnancies in Zambia is attributable to unobserved community level factors. The Wanatabe - Aikake Information Criteria (WAIC shows that models, which includes all the individual and community level factors (although the difference between individual and community level factors in minimal) are better fit compared to intercept only and individual levels factors only models. As such, the interpretation of results focused mainly on the model 3 , which consists of all the independent variables in the study.

The survey year confirms the crude analysis that emerged in the bivariate analysis where teenage pregnancies seemed to increase over time in most of the variables. After adjusting for the influence of all included variables, the odds of teenage pregnancy increased by 1.56 times in 2007 compared to 2001 . The increased odds of early pregnancy are observed in the subsequent survey years of 2014 and 2018 albeit with relatively reduced odds. Other significant predictors of teenage pregnancy and early motherhood include age, literacy levels, employment status, marital status, knowledge of fertile period and visiting health facilities. The odds of early pregnancy among young women age 18-19 were 2.57 times higher than young women age group 15-17. Married teenagers have much higher odds (8.33) of being pregnant than their unmarried counterparts.

Knowledge of fertile period shows surprising results whereby young women who know the fertile period are 1.69 times more likely to be pregnant than those who do not know. Being literate reduces the odds of early pregnancy by 0.76 while being in employment increases the odds of teenage pregnancy by 1.24 times. Young women who had initiated sexual activities at a later age of 18-19 had significantly reduced odds (0.32) of early pregnancy compared to those who did so before age 18 . Visiting health facilities in the last 12 months does not seem to be a cushion for teenage pregnancy since those who visited health facilities had significantly higher odds of teenage pregnancy than those did not. Exposure to family planning messages, however, reduces odds of teenage pregnancy by 0.59 . Poverty is also a significant predictor of teenage pregnancy as young women who belong to wealthier households have less odds of 
having early pregnancies compared to those from poorer backgrounds. Educational status and knowledge of contraceptive methods are not significant predictors of teenage pregnancy in Zambia.

Community level factors were mostly not found to be significantly associated with the odds of early motherhood and teenage pregnancies except for community media family planning exposure, exemplifying the importance of mass media in health promotion. The results further show that living in communities with high exposure to family planning messages is associated with a reduction in the odds of early pregnancy. 
Table 3

Multilevel parameter estimates and odds of teenage pregnancy and early motherhood

\begin{tabular}{|c|c|c|c|}
\hline \multicolumn{4}{|l|}{ Variables } \\
\hline & Model 1 & Model 2 & Model 3 \\
\hline Intercept & $0.41[0.39,0.43]$ & $0.14[0.08,0.23]$ & $0.12[0.07,0.20]$ \\
\hline \multicolumn{4}{|l|}{ Survey year } \\
\hline 2001 & & 1 & 1 \\
\hline 2007 & & $2.56[2.00,3.33]$ & $2.59[2.03,3.34]$ \\
\hline 2014 & & $1.77[1.42,2.22]$ & $1.81[1.47,2.24]$ \\
\hline 2018 & & $1.56[1.26,1.93]$ & $1.57[1.27,3.13]$ \\
\hline \multicolumn{4}{|l|}{ Age } \\
\hline $15-17$ & & 1 & 1 \\
\hline 18-19 & & $2.55[2.19,2.95]$ & $2.57[2.20,2.98]$ \\
\hline \multicolumn{4}{|c|}{ Educational level } \\
\hline No education & & 1 & 1 \\
\hline Primary & & $1.12[0.75,1.67$ & $1.12[0.76,1.66]$ \\
\hline Secondary & & $0.98[0.64,1.53]$ & $1.00[0.64,1.55]$ \\
\hline \multicolumn{4}{|l|}{ Literacy } \\
\hline Illiterate & & 1 & 1 \\
\hline Literate & & $0.74[0.63,0.88]$ & $0.76[0.64,0.90]$ \\
\hline \multicolumn{4}{|c|}{ Employment status } \\
\hline No & & 1 & 1 \\
\hline Yes & & $1.26[1.10,1.47]$ & $1.24[1.06,1.46]$ \\
\hline \multicolumn{4}{|l|}{ Wealth quintile } \\
\hline Poorest & & 1 & 1 \\
\hline Poorer & & $0.86[0.68,1.09]$ & $0.85[0.67,1.08]$ \\
\hline Middle & & $0.76[0.60,0.95]$ & $0.74[0.55,0.95]$ \\
\hline Richer & & $0.78[0.61,0.99]$ & $0.73[0.50,0.95]$ \\
\hline Richest & & $0.43[0.33,0.57]$ & $0.39[0.28,0.54]$ \\
\hline
\end{tabular}




\begin{tabular}{|c|c|c|c|}
\hline \multirow[t]{2}{*}{ Variables } & \multirow{2}{*}{ Model 1} & \multirow[b]{2}{*}{ Model 2} & \multirow[b]{2}{*}{ Model 3} \\
\hline & & & \\
\hline \multicolumn{4}{|l|}{ Marital status } \\
\hline Never married & & 1 & 1 \\
\hline Married & & $8.40[6.93,10.25]$ & $8.33[6.84,10.26]$ \\
\hline Formerly married & & $5.13[3.08,8.69]$ & $5.11[3.18,8.25]$ \\
\hline \multicolumn{4}{|c|}{ Knows fertile period } \\
\hline No & & 1 & 1 \\
\hline Yes & & $1.68[1.42,1.99]$ & $1.69[1.43,2.00]$ \\
\hline \multicolumn{4}{|l|}{ Age at first sex } \\
\hline $10-14$ & & 1 & 1 \\
\hline $15-17$ & & $0.87[0.73,1.03]$ & $0.88[0.74,1.04]$ \\
\hline $18-19$ & & $0.32[0.24,0.42]$ & $0.32[0.23,0.43]$ \\
\hline
\end{tabular}

Knowledge of any contraceptive method

\begin{tabular}{lll} 
No & 1 & 1 \\
\hline Yes & $1.59[0.98,2.62]$ & $1.58[0.97,2.62]$
\end{tabular}

\section{Exposure to media FP messages}

\begin{tabular}{lll} 
No & 1 & 1 \\
\hline Yes & $0.60[0.52,0.71]$ & $0.59[0.50,0.71]$
\end{tabular}

Visited health facility last 12 months

\begin{tabular}{lll} 
No & 1 & 1 \\
\hline Yes & $3.69[3.21,4.27]$ & $3.72[3.23,4.30]$ \\
\hline Contextual variables & & \\
\hline Place of residence & 1 \\
\hline Urban & $1.11[0.93,1.32]$ \\
\hline Rural & \\
\hline Community education & 1 \\
\hline Low & $1.05[0.88,1.25]$ \\
\hline High & \\
\hline
\end{tabular}




\begin{tabular}{|c|c|c|c|}
\hline \multicolumn{4}{|l|}{ Variables } \\
\hline & Model 1 & Model 2 & Model 3 \\
\hline \multicolumn{4}{|c|}{ Community poverty } \\
\hline Low & & & 1 \\
\hline High & & & $1.11[0.85,1.44]$ \\
\hline \multicolumn{4}{|c|}{ Community media FP exposure } \\
\hline Low & & & 1 \\
\hline High & & & $0.82[0.70,0.96]$ \\
\hline \multicolumn{4}{|c|}{ Random effects } \\
\hline Variance (SE) & $0.38(0.04)$ & $0.31(0.09)$ & $0.30(0.11)$ \\
\hline VPC (\%) & 10.4 & 8.61 & 8.36 \\
\hline WAIC & 12310.6 & 4951.8 & 4951.2 \\
\hline
\end{tabular}

\section{Discussion}

This study sought to analyse the trends and factors associated with teenage pregnancy and early motherhood using multilevel modelling of ZDHS data between 2001 and 2018. The study focused on the influence of both individual and community level factors on teenage pregnancy as well as how these factors vary between clusters. Our review of literature reveals that no known comprehensive study of this nature has been conducted in Zambia and thus bolstering the importance of our findings. The significant findings indicate that overall, there is an increase in teenage pregnancies in Zambia. However, there are apparent disparities in the trends of early pregnancies among different groups of teenagers. Teenagers who are 15 years old, live in rural areas and are from poorest households reported an increase in early pregnancy over the four surveys analysed for this study. The increase in the trends of early pregnancy was also observed among those illiterate and married/formerly married teenage women. An apparent decline in teenage pregnancy was observed among young women who are exposed to family planning messages and for those who know their fertile periods.

At the individual level, we found that marital status was strongly associated with teenage pregnancy. Teenagers that reported being currently married or those living with partners were more likely to be pregnant compared to their never-married counterparts. These findings are consistent with evidence from other previous studies in Zambia $(4,20)$ and Africa $(3)$. The relationship between marital status and early pregnancy has long been held in literature (6). Once married, the pressure to have a baby is often high on young couples because of the economic and social value that is attached to childbearing in most African 
societies (21). In the same vein, marriage is a protection from societal stigma for due to the social expectation of childbearing among married women.

Poverty equally plays a crucial role in motivating both early marriages and early pregnancy. In their qualitative study looking at parallel discourses on early pregnancy in rural Zambia, (6) found poverty to be a prominent factor in early marriages, both from the parents and young women's perspective. Parents want to marry off their young girls for cash from bride-wealth while young girls are motivated to leave their parents' homes because of the failure by parents to meet basic needs such as school fees and other daily necessities. Our study also confirms the role of poverty in early pregnancy and early marriages as we find that teenagers from wealthier households are less likely to have early pregnancies compared to those from poorer backgrounds. Similar findings were reported by a previous study on the same population in Zambia (4).

As expected, older teenagers have higher odds of early pregnancy than younger ones because they are likely to be more sexually active and exposed and thus being predisposed to early pregnancy. The fact that the higher odds of pregnancy among older teenagers remained significant even after controlling for age at sexual debut means that it is an important predictor of teenage pregnancy. It is still possible however, that younger teenagers are less likely to report sexual activities due to social and institutional barriers (22). A complex interchange of factors is likely to be at play to explain old teenage and pregnancy. Family and peer pressure to have boyfriends and get married as elucidated by (23) is more likely to be felt the most by older teenagers. Furthermore, older teenagers are more likely to experience peer and parental pressure to be married. Another dynamic, which is likely to make older teenagers be more exposed to early pregnancy, is the veil of secrecy that is attached to sexual and contraceptive topics in traditional family setup in Zambia. This brings challenges of access to authentic information on sexual reproductive health.

Unlike many similar previous studies (3-5) our research does not find a significant relationship between educational qualification and teenage pregnancy. However, this result is consistent with a study from Bangladesh (24) which also did not find educational qualification to be significantly affect early marital pregnancy. This study instead, finds literacy to be an important predictor of early pregnancy. Illiterate young women have higher odds of getting pregnant compared to literate ones. We suspect that correlation between literacy levels and educational qualification must have accounted for the nonsignificance of the latter in this study. It is plausible that literate women would be more empowered with the skills to prevent pregnancy than their illiterate counterparts would. Since literacy is directly associated with educational status, it is reasonable that in Africa, teenage who are out of school are more likely to get pregnant and have an early start to childbearing than those who are in school (3). This could also be the reason for high prevalent rates of teenage pregnancy and early marriages in sub-Saharan Africa where almost one third of teenagers are out of school (25). Literate women are expected to have better access to sexual education and be better informed about sexual, health and reproductive rights that help them to avoid early and risky behaviours. 
The results from this study indicate that early sexual debut increases the odds of early pregnancy. Sexual debut is a proxy measure of a woman's onset exposure to pregnancy due to the widespread nature of premarital sex in most societies (26). The link between early sexual debut and early pregnancy is obvious. Early sexual debut exposes young girls to risks of pregnancy at their most fertile ages, keeps them at risk of pregnancy longer due to their younger ages at sexual debut and elongates their reproductive lifespan compared to their counterparts that initiate sex late especially in relation to inadequate sexual education and contraceptive use. A study in East Africa also had similar findings (26). In Zambia, some studies have pointed to the role played by social norms and the pressure for material gains as influencing factors for young girls to engage in early sexual debut and subsequently early pregnancy $(6,23)$. Zambia's social norms on sexual behaviour are anchored in secrecy and religion. Svanemyr's study reported that no parents indicated lack of adequate knowledge on risks of unprotected sex as the reason for early pregnancy.

Inadequate contraceptive use is also another critical factor that was not mentioned by parents and yet crucial in early pregnancy prevention (5). The secrecy around sex topics between parents and children illuminated by social and cultural norms is a major contributing factor for early sexual debut (3). Pressure for material benefits has previously been constructed as a parallel and non-dominant narrative of sexual behaviour and early pregnancy and yet very common especially in rural Zambia $(6,23)$.

Media exposure is significantly associated with early pregnancy among teenagers in this study. Teenagers who are exposed to family planning messages are less likely to have early pregnancy. Other studies conducted in sub-Saharan Africa found this relationship to be statistically significant $(27,28)$ Family planning messages reinforces the knowledge base of young people on safer sex and contraceptive use which prevents early pregnancy. It is unconceivable that only radio and television messages on family planning would contribute to a reduction in teenage pregnancy. Disseminating of such information has become relatively easier in this era of improved technology where mobile communication gadgets are carried everywhere, coupled with enhanced ways of sharing information through social media and other related platforms.

Surprisingly, knowledge of fertile period, employment status and recent visits to a health facility were associated with higher odds of teenage pregnancy. These results seem to validate claims of rational choice in early pregnancy as made by some scholars (4). They posit that early pregnancy in developing countries may be more intended than in developed countries in view of social and cultural norms that seem to encourage the practice. Our results, which show that young women with knowledge of the fertile period had higher odds of falling pregnant which pregnancies, could be intentional. Similarly, results, which indicate those employed as being more likely to have early pregnancy, may suggest that they rationally decided to get pregnant because of the financial security their employment brings to taking care of children.

The influence of contextual factors on early pregnancy have been thought provoking. This study found that variations in early pregnancies are mostly attributable to individual level factors. However, some 
significant variations were also observed between communities. Apart from community family planning messages, none of the contextual factors have been found to predict teenage pregnancy. Even more startling is the finding that place of residence, which has always been found to be associated with teenage pregnancy was not the case in our study. A Zambian study focusing on a similar population group reported that rural young women are more likely to have early pregnancy compared to their urban counterparts $(4,29)$. However, our study is significantly different as it pools data from four surveys compared to just one analysed by Munakampe and colleagues. Findings demonstrate the presence of other factors, which may be more important than residence are influencing sexual activities among young people and subsequently early pregnancy.

\section{Conclusion}

This trends analysis shows that early pregnancy remains a social and public health challenge in Zambia as the country has experienced little decrease in the years under consideration. The major factors associated with early pregnancy include age, marital status, and employment, knowledge of fertility period, wealth quintile, sexual debut and media family planning messaging at individual level. Only community media family planning messaging was associated with early pregnancy among contextual factors. Most of variations in teenage pregnancy were attributable to individual level factors but community level characteristics made a significant contribution. The study suggests that early marriage and early pregnancy are intertwined. Stakeholders need to prioritise the fight against early marriage in order to prevent pregnancy in teenagers. Emphasis should be put on improving literacy levels and the general fight against poverty. Considering the fact that social and cultural norms may be preventing parents and children to discuss sex topics in Zambia, it is important to encourage sexual health education promotion through the mass media such as Newspaper, Television (TV), Radio and Social media.

\section{Limitations and strengths of the study}

The 2018 ZDHS data were collected through a cross-sectional study design that does not permit measurement of causation. Although DHS data cannot facilitate causal inferences, DHS's use nationally representative sample, which allows for the generalizability of study findings to the whole country, demonstrates its strength in measuring country-level outcomes important for policy implications. In addition, the rigor of the DHS methodology generally validates the quality of data and outcomes therefrom. The results of this study are comparable across countries where the DHS is conducted. As such, this study makes a significant contribution to the body of knowledge in terms of understanding contextual factors influencing teenage pregnancy and early motherhood in Zambia.

\section{Abbreviations}

$\mathrm{Cl}$ Confidence Interval 
CrL Credible Intervals

DHS Demographic and Health Survey

EA Enumeration Area

FP Family Planning

SDG Sustainable Development Goal

SRH Sexual Reproductive Health

SSA Sub-Saharan Africa

UN United Nations

UNFPA United Nations Population Fund

UNICEF United Nations Children Fund

USAID United States Aid for International Development

WHO World Health Organisation

ZDHS Zambia Demographic and Health Survey

\section{Declarations}

\section{Ethical approval and consent to participate}

Secondary data sources were utilised in the study. The DHS programme granted permission to use DHS datasets. There are no personal identifiers for survey participants in the DHS files. The country ethical review boards as well as those for the Centers for Disease Control and Prevention (CDC) Atlanta approved all survey protocols. The ZDHS data collection process required approval from participants age 18 and older. Before seeking consent from the legal minors, the DHS protocol required assent from parents/guardians for all participants 15-17 years.

\section{Consent for publication}

Not applicable

\section{Availability of data and materials}

Data used in our study is publicly available at DHS program website (https://dhsprogram.com/). 


\section{Competing Interests}

Authors declare no competing interests.

\section{Funding}

No funding was received from any organization or institution.

\section{Author Contributions}

MP developed the concept for this study, prepared the methodology and wrote the interpretation text for the manuscript for descriptive analysis. NM prepared the background and performed overall review and editing. MEK and MS performed the descriptive and inferential analysis. SS preformed multilevel analysis and wrote discussion of findings and conclusion. MP, SJM and NM reviewed the manuscript for intellectual content. All authors have read and approved the final version of this manuscript.

\section{Acknowledgements}

We express our gratitude to the Zambia Statistics Agency and the DHS program for authorizing the use of the ZDHS datasets from 2001 to 2018 and for providing us with the DHS reports, which were useful to the process of developing this manuscript.

\section{References}

1. Ochen AM, Chi PC, Lawoko S. Predictors of teenage pregnancy among girls aged 13-19 years in Uganda: a community based case-control study. BMC Pregnancy Childbirth. 2019 Dec;19(1):211.

2. Neal S, Channon AA, Chandra-Mouli V, Madise N. Trends in adolescent first births in sub-Saharan Africa: a tale of increasing inequity? Int J Equity Health. 2020 Dec;19(1):151.

3. Kassa GM, Arowojolu AO, Odukogbe AA, Yalew AW. Prevalence and determinants of adolescent pregnancy in Africa: a systematic review and Meta-analysis. Reprod Health. 2018 Dec;15(1):195.

4. Munakampe MN, Fwemba I, Zulu JM, Michelo C. Association between socioeconomic status and fertility among adolescents aged 15 to 19: an analysis of the 2013/2014 Zambia Demographic Health Survey (ZDHS). Reprod Health. 2021 Dec;18(1):182.

5. Jonas K, Crutzen R, Borne B, Sewpaul R, Reddy S. Teenage pregnancy rates and associations with other health risk behaviours: A three-wave cross-sectional study among South African school-going adolescents. Reprod Health. 2016 May 4;13. 
6. Blystad A, Moland KM, Munsaka E, Sandøy I, Zulu J. Vanilla bisquits and lobola bridewealth: parallel discourses on early pregnancy and schooling in rural Zambia. BMC Public Health. 2020 Dec;20(1):1485.

7. UNFPA. Girlhood. Not Motherhood: Preventing Teenage Pregnancy [Internet]. New York: UNFPA: UNFPA; 2015 [cited 2021 Jul 12]. Available from: https://www.unfpa.org/sites/default/files/pubpdf/Girlhood_not_motherhood_final_web.pdf.

8. Population Council UNFPA. Adolescent pregnancy in Zambia. Policy Brief [Internet]. Lusaka, Zambia: Population Council, UNFPA; 2017. Available from: https://www.who.int/news-room/factsheets/detail/adolescent-pregnancy.

9. World Health Organization. World Health Statistics 2021: Monitoring Health for the SDGs, sustainable development goals. Geneva: World Health Organization; 2021b.

10. World Health Organization. Adolescent pregnancy. Geneva: World Health Organization; 2021a.

11. World Health Organization. World Health Statistics 2021: Monitoring Health for the SDGs, sustainable development goals. 2021.

12. Alemayehu T, Haider J, Habte D. Determinants of adolescent fertility in Ethiopia. Ethiop J Health Dev [Internet]. 2010 [cited 2021 Dec 9];24(1). Available from: https://www.ajol.info/index.php/ejhd/article/view/62942.

13. Zambia Statistics Agency. Ministry of Health (MOH) Zambia, and ICF. Zambia Demographic and Health Survey 2018. Lusaka, Zambia, and Rockville. Maryland: Zambia Statistics Agency, Ministry of Health, and ICF; 2019.

14. Zambia Statistics Agency. 2018 Zambia Demographic and Health Survey. Zambia Statistics Agency; 2020.

15. Croft TN, Marshall AMJ, Allen CK. Guide to DHS Statistics [Internet]. Rockville: ICF; 2018. Available from: www.DHSprogram.com.

16. Goldstein H. Preface Acknowledgements Glossary Notation.

17. Merlo J. A brief conceptual tutorial of multilevel analysis in social epidemiology: linking the statistical concept of clustering to the idea of contextual phenomenon. J Epidemiol Community Health. 2005 Jun;59(6)(1):443-9.

18. Bürkner P-C. Advanced Bayesian Multilevel Modeling with the R Package brms. ArXiv170511123 Stat [Internet]. 2017 Oct 15 [cited 2021 Dec 10]; Available from: http://arxiv.org/abs/1705.11123.

19. Watanabe S. Asymptotic Equivalence of Bayes Cross Validation and Widely Applicable Information Criterion in Singular Learning Theory::24.

20. Namukoko H, Ndonyo R, Hamoonga E, Phiri M. Unmet Need for Family Planning Among Married Women in Zambia: Lessons from the 2018 Demographic and Health Survey. 2021.

21. Ezeah P. Marriage and Motherhood: A Study of the Reproductive Health Status and Needs of Married Adolescent Girls in Nsukka, Nigeria. J Sociol Soc Anthropol. 2012 Jul;3(1)(1):1-6. 
22. Chandra-Mouli V, McCarraher DR, Phillips SJ, Williamson NE, Hainsworth G. Contraception for adolescents in low and middle income countries: needs, barriers, and access. Reprod Health. 2014 Dec;11(1):1.

23. Svanemyr J. Adolescent pregnancy and social norms in Zambia. Cult Health Sex. 2020 Jun 2;22(6):615-29.

24. Sayem A, Nury ATM. Factors associated with teenage marital pregnancy among Bangladeshi women. Reprod Health. 2011 May;20:8:16.

25. UNFPA. Adolescent pregnancy: a review of the evidence. New York: UNFPA: UNFPA; 2013.

26. Zaba B, Pisani E, Slaymaker E, Ties B. Age at first sex: Understanding recent trends in African demographic surveys. Sex Transm Infect. 2005 Jan 1;80 Suppl 2:ii28-35.

27. Meekers D, Van Rossem R, Silva M, Koleros A. The Reach and Effect of Radio Communication Campaigns on Condom Use in Malawi. Stud Fam Plann. 2007 Jun;38(2):113-20.

28. Okigbo C, Speizer I, Corroon M, Gueye A. Exposure to family planning messages and modern contraceptive use among men in urban Kenya, Nigeria, and Senegal: A cross-sectional study. Reprod Health. 2015 Jul 22;12.

29. Phiri M, Banda C, Lemba M. Why is Zambia's Rural Fertility Declining at Slow Pace? A Review of DHS Data 1992-2018. International Journal of Research Publication Reviews. 2020;1(2):5-16. 